Motrivivência Ano XXI, No 32/33, P. 230-257 Jun-Dez./2009

\title{
CULTURA ESCOLAR, VIDA DAS ESCOLAS E EDUCAÇÃO FÍSICA ESCOLAR: balanço e perspectivas
}

Santiago Pich'

\begin{abstract}
Resumo
O presente trabalho tem como objeto apresentar as principais contribuições teóricas na elaboração do conceito de cultura escolar e analisar a sua recepção no campo da Educação
\end{abstract} Física. Entendemos que o conceito de cultura escolar pode ser um rico horizonte teórico de pesquisa para compreendermos o "sendo" da Educação Física escolar, as maneiras de produção de uma cultura escolar específica da Educação Física no cotidiano escolar. Nesse sentido, propomos alguns princípios teóricometodológicos para os estudos balizados pelo conceito de cultura escolar, bem como apontamos possíveis desdobramentos de pesquisa.

Palavras-chave: Cultura escolar; Educação Física escolar; pedagogia progressista.

\section{Abstract}

This paper aims to present the most important theoretical contributions on the school culture concept and to analyze its reception in the Brazilian physical education academic field. We assume as a start point that the school culture concept could be a fertile research theoretical horizon in comprehending the "being" of the physical education, the specific ways in producing a specific physical education school culture in the context of the school day-to-day. In this sense, we propose some theoretical-methodological principles for researches oriented by the school concept culture, as well we point out possible research objects based on that concept.

Key-words: School Culture; Physical Education; progressive pedagogy.

1 Doutor em Ciências Humanas (PPGICH/UFSC) - Professor do Curso de Educação Física UNIVALI, Itajaí - SC. Contato: santiagopich@yahoo.com 
Ano XXI, n 32/33, junho e dezembro/2009

\section{Introdução}

A produção de conhecimento da pedagogia da Educação Física brasileira tem transitado por diversos momentos desde a década de 80 até a atualidade, passando por fases que privilegiaram diversos tipos de elaborações teóricas. No primeiro movimento assistimos a construção de propostas pedagógicas para o campo escolar, posteriormente emergiram com maior vigor os estudos que procuraram dar protagonismo aos atores do cotidiano escolar e dar ouvidos às suas vozes; atualmente estamos presenciando um movimento que tem sua referência mais importante na cultura que é produzida na escola, e que, dentre outras possibilidades, tem no conceito de cultura escolar uma das mais importantes ferramentas teóricas.

Esse novo olhar sobre o campo escolar constitui-se num promissor horizonte, porque permite superar a visão da escola e da Educação Física enquanto um simples espaço de reprodução, como um epifenômeno de processos sociais mais amplos; seja como um mero lugar de reprodução do esporte espetáculo e de rendimento, seja como um espaço de implantação linear de políticas públicas de Educação.

Para exemplificar o que dizemos, nos valemos do ordenamento legal do sistema educacional vigente no Brasil. A Lei de Diretrizes e Bases da Educação Brasileira (LDB, 9394/96) foi amplamente celebrada pelo campo da Educação Física, uma vez que estabelecia a passagem do caráter da Educação Física escolar de "atividade" para "componente curricular". Reconhece-se assim, em tese, no plano legal a relevância do papel do conhecimento específico da Educação Física na formação do cidadão. Também assistimos na década de 90 à elaboração dos Parâmetros Curriculares Nacionais e de Propostas Curriculares nos níveis estadual e municipal. Contudo, a realidade presente no campo escolar não nos permite apontar avanços, no sentido da superação da concepção de Educação Física escolar calcada na aptidão físico-esportiva, fortemente criticada pelo movimento renovador da Educação Física brasileira, em particular pela vertente progressista. Se as mudanças no cotidiano escolar se operassem por decreto, bastaria analisar os documentos ou elaborarmos propostas teóricas para o campo escolar, para sabermos o que acontece no cotidiano escolar. Felizmente não é assim. A escola possui uma dinâmica própria, produz uma cultura específica que é preciso compreender a partir de uma aguçada capacidade para "ler o cotidiano". É preciso adentrar nos ambientes em que essa cultura 
é produzida para decifrar seus códigos, normas, valores e práticas. Se durante um longo tempo procuramos "legislar" sobre a escola e seus atores, estamos atualmente perante o desafio de descer da torre de marfim acadêmica para termos uma relação colaborativa com os atores do cotidiano escolar, uma relação sujeito-sujeito e não mais sujeito-objeto, para termos alguma chance de o campo acadêmico poder contribuir efetivamente com a transformação da Educação Física escolar. Entendemos que as pesquisas referenciadas no conceito de cultura escolar podem ser um terreno fértil para caminharmos nessa direção.

Nesse sentido nos propomos no presente trabalho analisar as pesquisas produzidas no campo da Educação Física escolar balizadas pela concepção de que a escola é produtora de uma cultura específica, procurando identificar seus alcances e limites. Além disso, procuramos apontar perspectivas de pesquisa e princípios teórico-metodológicos para contribuir com a orientação de futuros desdobramentos das mesmas. Para tanto, o artigo se compõe de três partes. Na primeira realizamos uma rápida e esquemática análise da trajetória da produção de conhecimento na pedagogia da Educação Física brasileira a partir dos anos 90, privilegiando a produção da corrente pedagógica progressista; na segunda parte realizamos uma breve genealogia dos estudos sobre escola e cultura e/ou cultura escolar e apresentamos os principais autores desta corrente e sua recepção nas pesquisas da Educação Física escolar; e, finalmente, apontamos possíveis perspectivas de pesquisa e alguns princípios teórico-metodológicos que podem orientar tais empreendimentos investigativos.

\section{A produção de conhecimento na pedagogia da Educação Física brasileira: do sujeito ausente ao protagonismo da vida das escolas}

Embora, seja possível reconhecer no campo acadêmico um significativo avanço na produção de propostas pedagógicas para a Educação Física escolar, ainda observamos que a apropriação dessas idéias pelo campo escolar, está muito distante de se concretizar. O Prof. Elenor Kunz alertava já no início da década de 90 sobre esse distanciamento. Ele afirmava que:

[...] embora o número de profissionais críticos tenha aumentado muito ultimamente - na área da Educação, especialmente - com a diminuição das resistências internas quanto aos 're- 
Ano XXI, n 32/33, junho e dezembro/2009

volucionários' da Educação, as propostas 'transformadoras' ou de mudanças ainda não passaram de um nível crítico-teórico (KUNZ, 1991, p. 129).

A preocupação sobre a falta de diálogo entre as produções teóricas da pedagogia da Educação (Física) brasileira e os atores do campo da Educação Física escolar expressada pelos autores supracitados continuará a estar presente em estudos posteriores, porém com novos matizes.

Esse movimento nos permite exemplificar a crescente preocupação observada ao longo da década de 90, na pedagogia da Educação Física brasileira no sentido de aproximar o campo acadêmico do campo escolar. Entretanto, devemos reconhecer que essa aproximação se deu a partir do pressuposto (nem sempre explícito, nem reconhecido) da primazia do campo acadêmico por sobre o campo escolar. Dito de outra maneira, os atores do campo acadêmico continuaram a produzir propostas "para" o campo escolar, ignorando, via de regra, a "vida das escolas". A despeito da preocupação dos intelectuais da Educação Física com mudanças efetivas no campo escolar, pode-se suspeitar que as lentes teóricas que orientaram essas produções não permitiam compreender cabalmente o cotidia- no escolar para pensar, a partir dele, as possibilidades de mudanças. As palavras de um dos protagonistas do movimento renovador da Educação Física brasileira, o Prof. Mauro Betti, resumem bem o sentimento e a avaliação do período aqui discutido por parte desses atores:

Incomodados, em crise e cheios de dúvidas, fomos às diversas disciplinas científicas e à filosofia, em um primeiro movimento, para melhor compreender a Educação Física, e depois, realimentar o nosso projeto de Educação Física. Mas a maioria de nós, fascinados pelas respostas encontradas (às vezes de modo muito fácil e rápido), passamos a acreditar demasiadamente nelas, e estamos sendo incapazes de concretizar este segundo movimento, de retorno ao interior da Educação Física viva, para re-interrogar nossas dúvidas e a cada momento nos remetermos ao projeto inicial que nos impulsionou (BETTI, 2005).

Entre a segunda metade da década de 90 e o início dos anos 2000, observamos uma nova corrente de pesquisa da Educação Física escolar que objetiva compreender a vida dos professores das escolas, sendo os objetos mais importantes: a compreensão de 
como se constituem os saberes docentes (LOCATELLI, FERREIRA NETO, DOS SANTOS, 2003), as trajetórias biográficas dos professores (FIGUEREDO, 2004), os processos de socialização profissional, (FARIA, SHIGUNOV, NASCIMENTO, 2001), a relação entre o trabalho docente e a síndrome de esgotamento profissional (SANTINI et al., 2003), a maneira como se legitima a Educação Física nas instituições escolares (CARDOSO, 2001), e as possibilidades de trabalho colaborativo entre as universidades e as escolas a partir da pesquisa-ação (BRACHT et al. 2001), para situar as temáticas mais relevantes. Nesse sentido, destacamos os estudos conduzidos e/ou orientados pelo Prof. Vicente Molina Neto e desenvolvidos no Grupo de Pesquisa F3p-efice (MOLINA NETO, 1999; MOLINA NETO, SANTINI, 2005; MOLINA NETO, SCHNEIDER, 2000), e pelo Professor Valter Bracht e desenvolvidos no âmbito do Laboratório de Estudos em Educação Física (LESEF) (BRACHT et. al, 1999; 2001, 2003). Estas pesquisas também apresentam um novo enfoque metodológico. Se antes as produções se orientavam por uma transposição (quase)linear entre produções teóricas do âmbito da pedagogia e da epistemologia da Educação Física e da sociologia do esporte, neste movimento predominam os estudos qualitativos, os de cunho etnográfico e outros balizados pela pesquisa-ação.

Cumpre destacar, ainda, que os estudos assumem por vezes um viés "acusatório" com relação aos professores, culpando-os (nas entrelinhas) por desconhecerem as produções do campo acadêmico (BRACHT et al., 1999), e reproduzindo assim a lógica acima delineada sobre a supremacia do campo acadêmico sobre o escolar. Contudo, neste novo momento os professores de Educação Física escolar deixam de ser vistos como aqueles que "sofrem" o conhecimento produzido no campo acadêmico e passam a ser concebidos como sujeitos que produzem conhecimentos próprios sobre o cotidiano escolar para orientar sua prática pedagógica.

Entre o final da década de 90 e início da presente década configura-se uma nova vertente de estudos da Educação Física escolar que, dando continuidade e motivado, em boa medida, pelos estudos anteriormente referidos, assume como principal referência a compreensão da escola como um espaço de produção de uma cultura específica, a cultura escolar, e não mais como um espaço de mera reprodução de processos macrosociais, como por exemplo, o esporte de rendimento. Neste campo situamos os estudos desenvolvidos e/ou orientados pelos professores 
Ano XXI, n 32/33, junho e dezembro/2009

Valter Bracht, Fernando J. González e Paulo Fensterseifer, (FENSTERSEIFER, ALMEIDA, 2007; BRACHT et al., 2005, 2008; GONZALEZ, FENSTERSEIFER, 2006) e aqueles desenvolvidos por pesquisadores da historiografia da Educação (Física) brasileira, os professores Tarcísio M. Vago (VAGO, 1996, 1999a, 1999b, 2000a, 2000b, 2003) e Marcus A. Taborda de Oliveira (OLIVEIRA, 2001, 2002). A crescente relevância dos estudos balizados pela categoria de cultura escolar ou por referências próximas nos abre um promissor horizonte de pesquisa para melhor compreender o cotidiano escolar, a vida dos professores e estabelecer um fértil diálogo entre o campo acadêmico e o campo escolar. Nesse sentido, a escola deixa de ser compreendida a parti de pré-supostos assumidos a-priori, e os professores não são mais julgados como reprodutores passivos de determinações macro-estruturais.

A instituição social escola é concebida como um espaço complexo de tensões entre fortes condicionamentos externos à escola e formas de produção de saberes e fazeres escolares que não podem ser simplesmente derivados de outras fontes que não sejam a vida das escolas e a biografia do(a) professor(a). Um denominador comum desses estudos é o pressuposto teórico-metodológico que concebe a escola com um espaço de produção de uma cultura própria. Para designar (e instituir) essa realidade, teóricos contemporâneos da educação têm se valido do conceito de cultura escolar.

Em virtude do conceito de cultura escolar ser de recente data e haver uma diversidade de posturas relativas ao mesmo, consideramos necessário situar, em primeiro lugar o conceito. Para tanto, realizamos uma breve genealogia dos estudos educacionais referenciados no conceito de cultura escolar, para, na seqüência, apresentar seus principais representantes e, paralelamente, analisar a sua recepção no campo da Educação Física brasileira. Finalmente, apresentaremos a proposta de alguns princípios teórico-metodológicos que poderão contribuir com o desenvolvimento de pesquisas balizadas pelo conceito de cultura escolar, bem como propomos alguns desdobramentos de pesquisa considerados relevantes para compreender a "vida" da Educação Física nas escolas brasileiras.

\section{Uma breve genealogia do conceito de cultura escolar}

Como tem sido comum, pelo menos desde a década de 80,0 campo acadêmico da Educação Física tem incorporado as tendências teóricas oriundas do campo da educação 
com uma defasagem de alguns anos. Não é diferente no caso da cultura escolar, e, de uma maneira mais ampla dos "estudos culturais".

Se observarmos o percurso das pesquisas educacionais, (e correndo o risco de cairmos num reducionismo que é sempre simplista) podemos dizer que até as décadas de 70 e 80 primavam os trabalhos de matriz marxista por um lado, e as pesquisas orientadas pela tese da reprodução de Bourdieu e Passeron, por outro. Nestes dois casos nos situamos em uma perspectiva teórica que privilegia a estrutura por sobre a singularidade, ou expresso em termos contemporâneos, se privilegia a determinação estrutural por sobre a ação.

Para apresentar a crítica feita a esta orientação da pesquisa educacional nos valemos das palavras do Prof. José Mário Pires Azanha, que produziu um dos primeiros trabalhos pautados no conceito de cultura escolar no campo da Educação brasileira, para resumir a necessidade de pesquisar a escola a partir de um novo olhar. Ele questionava em 1991 com muita lucidez:

Nem mesmo somos capazes, atualmente, de responder, de modo interessante à questão: 'o que é a escola?' Não nos iludamos com o número infindável de respostas que a pesqui- sa educacional tem dado para uma questão que parece tão simples. Os nossos vezos ideológicos e os nossos cacoetes pretensamente científicos já nos brindaram com uma multidão de esquemas classificatórios e de correlações estatísticas, mas desconhecemos inteiramente as relações efetivamente praticadas na escola (AZANHA, 1991, p. 38).

Vemos na década de 80 o início de uma inflexão com estudos de corte marxista, mas que refletem o interesse em descolar a infraestrutura da superestrutura, ou o que equivale a dizer a determinação material da dimensão cultural e simbólica. Neste caso temos um exemplo no livro de Paul Willis "Aprendendo a ser trabalhador Escola, resistência e reprodução social", que, ainda impregnado de uma visão reprodutivista, procura demonstrar como a dimensão da cultura se comporta como um agente formador do indivíduo para adaptá-lo à função social que a ordem social vigente lhe tem reservado (WILLIS, 1991). Porém, os autores que se ocuparão com os estudos culturais na educação na perspectiva dos estudos culturais atuais são Jean-Claude Forquin, e seu já clássico, "Escola e Cultura as bases epistemológicas e sociais 
Ano XXI, n 32/33, junho e dezembro/2009

do conhecimento escolar"; André Chervel e Dominique Julia que inauguraram os estudos sobre a história das disciplinas escolares, Antonio Viñao Frago que se ocupou principalmente com a relação entre a história das disciplinas, a cultura escolar e as reformas educacionais, e Angel Ignacio Pérez Gomes que procurou situar as diferentes culturas que, na sua permanente tensão, configuram a cultura escola.

Por outro lado, merece ser apontada outra inflexão na matriz epistemológica que baliza os estudos educacionais, em particular naqueles de corte historiográfico. Neste caso, se observa uma mudança que desloca a atenção das "idéias educacionais" ou para o cotidiano escolar, para o questionamento das relações concretas e situadas em instituições particulares (FARIA FILHO et al., 2004). Neste novo movimento de estudos educacionais, procura-se entender em que medida a "cultura escolar" é atravessada, influenciada ou contesta as elaborações teóricas e os dispositivos políticos produzidos nos âmbitos acadêmico e/ou governamental, evitando deduzi-la desses últimos.

Se nos perguntamos quais são as características desta nova corrente de estudos educacionais (e respondendo novamente de maneira esquemática) podemos dizer que eles compartilham de um princípio teórico comum, qual seja o do primado da ação. Esta nova perspectiva se pauta nas teorias da ação que privilegiam a diversidade e a singularidade dos indivíduos e das instituições (a "vida das escolas") em detrimento da determinação estrutural, da análise externalista. As escolas e seus atores passam a ser concebidos como agentes construtores do seu cotidiano, que detêm um alto ou relativamente elevado grau de autonomia para construí-lo.

É importante destacar, ainda, que não há uma postura unívoca quanto ao grau de autonomia da escola para a produção da sua vida, mas um leque de posicionamentos que, mesmo compartilhando do pressuposto antes mencionado, contemplam graus maiores ou menores de autonomia. Se nos pautamos por uma lógica de um continuum dessas posições podemos situar a Dominique Julia e André Chervel como aqueles que se posicionam no extremo de maior autonomia, isto é, de maior abertura à capacidade de ação da escola e seus agentes; enquanto Angel I. Pérez Gómez se situa no extremo oposto, que ainda atribui um peso considerável aos condicionantes estruturais. Entre eles se encontram Jean-Claude Forquin mais próximo de Julia e Chervel, e Antonio Viñao 
Frago que se aproxima da posição de Pérez Gómez. ${ }^{2}$

\section{As elaborações teóricas do conceito de cultura escolar e a sua recepção no campo acadêmico da Educação Físi- ca brasileira}

Aprendemos da história dos conceitos que a vida de um conceito depende da sua recepção. Consideramos necessário, portanto, realizar uma apresentação das principais posições sobre este conceito e situar, paralelamente, a recepção deste conceito no campo acadêmico da Educação Física brasileira. Temos particular interesse nesse aspecto, porque entendemos que a sua apropriação foi realizada de maneira aligeirada, e, com diferenças teórico-metodológicas importantes, se comparamos as produções da Educação Física com as os referenciais teóricos que as balizam.

Uma das posições mais favoráveis à ação é a de Dominique Julia. Esse autor se vale do conceito de cultura escolar para revisar a abordagem teórico-metodológica das pesquisas historiográficas no campo da Educação. Ele entende que a cultura escolar não pode ser estudada independentemente das suas interações e cruzamentos com outras esferas da cultura como as culturas religiosa, política ou a cultura popular. Para o autor:

[...] poder-se-ia descrever a cultura escolar como um conjunto de normas que definem conhecimentos a ensinar e condutas a inculcar, e um conjunto de práticas que permitem a transmissão desses conhecimentos e a incorporação desses comportamentos; normas e práticas coordenadas a finalidades que podem variar segundo as épocas (finalidades religiosas, sociopolíticas, ou simplesmente socialização). Normas e práticas não podem ser analisadas sem se levar em conta o corpo profissional dos agentes que são chamados a obedecer a essas ordens e, portanto, a

2 Outros autores tem sido referência nos estudos que trabalham com o conceito de cultura escolar no campo acadêmico da Educação Física brasileira, como Maurice Tardiff. No entanto, esse autor não se ocupa com o conceito, mas com o de saberes docentes. Neste artigo fizemos a opção por trabalharmos com os autores que se referem explicitamente ao conceito de cultura escolar. No entanto, cabe ressaltar que Tardiff pode ser considerado um autor que, do ponto de vista epistemológico, se posiciona muito próximo dos autores com os quais ora nos ocupamos. Alertamos, ainda, que não abordaremos o trabalho de Pérez Gómes, por não haver produção acadêmica na Educação Física que se referencie nesse autor. 
Ano XXI, n 32/33, junho e dezembro/2009

utilizar dispositivos pedagógicos encarregados de facilitar sua aplicação, a saber, os professores primários e os demais professores. Mas, para além dos limites da escola, pode-se buscar identificar, em um sentido mais amplo, modos de pensar e de agir largamente difundidos no interior de nossas sociedades, modos que não concebem a aquisição de conhecimentos e de habilidades senão por intermédio de processos formais de escolarização: aqui se encontra a escalada dos dispositivos propostas pela schooled society que seria preciso analisar; nova religião com seus mitos e seus ritos contra a qual Ivan Illich se levantou com vigor há mais de vinte anos. (JULIA, 2001, p. 11)

Destacamos da passagem que o autor concebe a cultura escolar como sendo constituída por três dimensões. Em primeiro lugar a cultura escolar depende de normas e práticas que visam formar os indivíduos que passam por um processo de educação formal conforme os interesses a que essas instituições se subordinam. Uma segunda dimensão diz respeito aos atores que são os responsáveis pela prática pedagógica, os professores. E finalmente aos interesses sociais situados fora da escola que entendem que a escola é o lócus privilegiado para a formação dos indivíduos. Assim, para qualquer pesquisa que se paute por este conceito essas três dimensões deveriam ser consideradas. Por outro lado, segundo Pessanha et al. (2004) para o autor ora discutido a cultura escolar também está marcada por mais três elementos: um espaço próprio, cursos de graduação para a formação profissional e os profissionais formados (aqui já referidos). Outro aspecto relevante na concepção de Julia é a diferenciação nas práticas escolares entre os níveis de escolarização, concebendo ele que haveria uma cultura escolar primária e outra secundária (JULIA, 2001).

Julia entende também que para compreender a escola é necessária a compreensão do "funcionamento interno" das escolas porque a tradição da pesquisa histórica tem sido "demasiado externalistas". Essa abordagem de pesquisa "[...] despreza as resistências, tensões e os apoios que os projetos têm encontrado no curso da sua execução" (JULIA, 2001, p. 12). Para se contrapor a essa tendência presente nos estudos historiográficos da educação, principalmente da história das idéias pedagógicas e da história das populações escolares, o autor entende que a história das disciplinas escolares propõe uma guinada para estudar o cotidiano escolar e 
abrir a "caixa preta" que os estudos pretéritos ignoravam (ibid., p. 13). Para Faria Filho et al., (2004, p. 144) "[...] Julia convidava os historiadores da educação a se interrogarem sobre as práticas cotidianas, sobre o funcionamento interno da escola".

Cabe destacar que o autor não desdenha os condicionantes macro-estruturais, porém coloca seu acento nas possibilidades criativas da escola. Na visão de Faria Filho et al. (2004, p. 144) "(Dominique Julia) externava sua crença, assim, nas inovações pedagógicas, esposando uma concepção de cultura escolar como inventiva". Nessa última idéia percebemos adequadamente retratada a posição de Julia com relação ao elevado grau de autonomia da escola para construir uma forma específica de relações com os condicionamentos de ordem estrutural.

Na Educação Física brasileira os autores que têm se apropriado do conceito de cultura escolar cunhado por Julia são Rosianny Campos Berto e Osmar Schneider também no campo da historiografia, mas neste caso da Educação Física escolar (BERTO e SCHNEIDER, s/d). O trabalho destes autores apresenta algumas diferenças metodológicas com relação aos princípios apontados pelo pesquisador francês, porque eles realizaram um trabalho a partir da revista Educação Physica como fonte, porém sem estabelecer as devidas mediações com as três dimensões apontadas por Julia. Este trabalho não avança no sentido de permitir compreender as relações entre a produção das representações da revista e sua recepção pelos atores escolares, pressupondo que essas representações operariam também como as dos professores de Educação Física. Assim, o trabalho corre o risco de cair em um reducionismo estruturalista, uma visão externalista, contra o qual o próprio Julia adverte.

André Chervel é outra referência fundamental para a compreensão do conceito de cultura escolar. Este autor, que muito influenciou outros expoentes da corrente de pesquisas sobre a história das disciplinas escolares, foi um dos mentores da corrente de pesquisas por ele denominadas de história das disciplinas escolares e que tem sua principal referência o texto "História das disciplinas escolares: reflexões sobre um campo de pesquisa" publicado no Brasil em $1990^{3}$. Nesse artigo o autor defende o estudo da história das disciplinas escolares em contraposição aos estudos tradicionais da educação, por

3 Em virtude de não termos tido acesso ao texto publicado no Brasil, trabalharemos neste artigo com o artigo publicado em 1991 na Revista "Educación" da Espanha. 
causa de os primeiros adentrarem na produção própria da escola, de um saber escolar, e por conceberem essa instituição social como um campo fértil de produção de uma cultura própria, a cultura escolar. A seguir reproduzimos a passagem mais emblemática do artigo para definir a postura do autor sobre a relação entre as disciplinas escolares e a cultura escolar:

Se tem sido possível atribuir à função educativa da escola um papel <estruturante> na história do ensino, é por causa de uma propriedade das disciplinas escolares. O estudo destas expõe claramente o caráter eminentemente criativo do sistema escolar e conduz, pois, a deixar no do supérfluo a imagem de uma escola reclusa na passividade, de uma escola receptáculo dos subprodutos culturais da sociedade. As disciplinas merecem o máximo interesse precisamente porque são criações espontâneas e originais do sistema escolar. E este, como possuidor de uma poder criativo insuficientemente valorado até o momento, desempenha dentro da sociedade um papel, do qual ninguém se deu conta que era duplo: em efeito, forma não somente indivíduos, mas também uma cultura, que penetra, por sua vez, na cultura da sociedade global, moldando-a, modificando-a (CHERVEL, 1991, p. 69)

Vemos na passagem acima o forte posicionamento do autor com relação ao caráter inventivo do conhecimento e da cultura escolar. Destacamos, ainda, que o autor entende que a cultura escolar, mesmo que não tenha sido percebido nos estudos educacionais (e talvez esse seja seu maior erro), detêm um potencial transformador da com relação à cultura global da sociedade. Vemos, assim, que as posições de Chervel e Julia se aproximam com relação à concepção de cultura escolar como um espaço criativo. Entretanto, consideramos oportuna a diferenciação entre eles que é apontada por Faria Filho et al. (2004, p. 146):

Chervel parecia afirmá-la de maneira mais contundente como original e se interessava principalmente pela construção dos saberes escolares. Julia fazia a ênfase da análise recair particularmente sobre as práticas escolares, o que levava a distinguir entre uma cultura escolar primária e uma cultura escolar secundária.

A mais importante referência ao trabalho de Chervel na Educação Física brasileira é o artigo do 
Prof. Tarcísio Mauro Vago intitulado "O 'esporte na escola' e o 'esporte da escola': da negação radical para uma relação de tensão permanente", que fora publicado em 1996 na Revista Movimento, e que teve ampla repercussão no campo acadêmico. Nesse momento Vago se vale da categoria de cultura escolar como baliza teórica para contestar a visão reprodutivista da Educação Física escolar presente, segundo ele, na análise da Educação Física escolar elaborada pelo Prof. Valter Bracht. O autor defende a idéia de Chervel e vê a escola como espaço de produção de cultura, cultura essa que pode influenciar a cultura global da sociedade. Vemos na seguinte passagem essa postura claramente retratada: "Aceita-se, então, a idéia de que não só é possível à escola produzir sua própria cultura escolar de esporte, como também a idéia de que é com essa cultura que a escola vai intervir na história cultural da sociedade" (VAGO, 1996, p. 12). Em momentos posteriores o autor vai se valer do pensamento de Dominique Julia e Antonio Viñao Frago de maneira complementar ao de André Chervel para construir seu processo argumentativo, como veremos mais adiante.

Embora não tenha se ocupado com desenvolver uma teorização sobre a cultura escolar, JeanClaude Forquin é uma importante referência sobre os estudos culturais na educação, particularmente seu livro "Escola e Cultura - as bases sociais e epistemológicas do conhecimento escolar". Para este autor a educação é um processo de apropriação de produções culturais. Nas palavras dele: "Educar, ensinar, é colocar alguém em presença de certos elementos da cultura a fim de que ele deles se nutra, que ele os incorpore à sua substância, que ele construa sua identidade intelectual e pessoal em função deles" (FORQUIN, 1993, p. 168). Como é amplamente conhecido, Forquin desenvolveu seu trabalho em torno das pesquisas sobre o currículo, porém, em virtude de considerar que este se assenta também sobre bases sociais e não somente epistemológicas, considera que a escola é também produtora de uma cultura específica. Ele distingue entre cultura da escola e cultura escolar para diferenciar a cultura no sentido antropológico, da escola como um espaço de produção de uma forma de vida própria, "como um mundo social", e no sentido didático-pedagógico, uma cultura do trabalho pedagógico. Para o autor:

[...] esta 'cultura da escola' (no sentido em que se também falar da 'cultura da oficina' ou da 'cultura da prisão') não deve ser confundida tampouco com o que 
Ano XXI, n 32/33, junho e dezembro/2009

se entende por 'cultura escolar', que se pode definir como o conjunto dos conteúdos cognitivos e simbólicos que, selecionados, organizados, 'normalizados', 'rotinizados', sob o efeito dos imperativos da didatização, constituem habitualmente o objeto de uma transmissão deliberada no contexto das escolas (lbid., p. 166).

Embora o livro acima citado seja uma importante contribuição para pensar a as relações entre escola e cultura, curiosamente não tem se constituído em uma referência para a produção de estudos sobre a cultura escolar no campo da Educação Física. As únicas apropriações do pensamento deste autor nos estudos pedagógicos da Educação Física que se valem da categoria de cultura escolar são o artigo de Tarcísio M. Vago sobre o esporte na $x$ da escola já mencionado, e, mais recentemente, em 2004 veio à luz um artigo de autoria de Marcílio Souza Júnior e Ana Maria de Oliveira Galvão que leva o título "História das disciplinas escolares e história da educação: algumas reflexões", que também se vale do pensamento de Forquin. Contudo, esses dois trabalhos, paradoxalmente, não se referenciam na obra mais relevante do sociólogo francês, mas em um artigo intitulado "Saberes escolares, imperativos didáticos, e dinâmicas sociais" publicado em 1992. No primeiro caso Vago se vale da releitura de Forquin sobre o conceito de transposição didática, concebendo-o como o processo de transformação de um objeto de saber científico em um objeto de ensino, que pressupõe a produção de um saber específico da escola, para se contrapor à visão de Valter Bracht sobre a maneira em que o esporte é tematizado na escola. Porém, o autor somente referencia Forquin como elo para introduzir no seu processo argumentativo o conceito de cultura escolar de André Chervel (VAGO, 1996). No segundo caso, a referência está relacionada com a concepção dos saberes escolares enquanto campo de disputa tanto na política interna da escola e da educação, bem como na tensão entre a instituição escolar com o contexto macro-social (SOUZA JÚNIOR, GALVÃO, 2004).

O último autor a que faremos referência neste tópico é Antonio Viñao Frago. Ele é professor de Teoria Educacional em Múrcia, Espanha e desenvolve há mais de uma década pesquisas na linha da história das disciplinas escolares pautado na categoria de cultura escolar. As contribuições teóricas de Dominique Julia e, principalmente, de André Chervel são importantes referências para este autor. Faremos 
uma apresentação mais demorada da proposta de Frago, por ser ele quem tem se ocupado em realizar uma elaboração teórica mais complexa deste conceito, bem como por ser a principal referência nos estudos pautados na categoria de cultura escolar, tanto no âmbito da Educação, quando da Educação Física ${ }^{4}$.

O artigo publicado no Brasil em 1995 que leva o título "Historia de la educación e historia cultural", cujo objeto é a apresentação de um programa sobre a história das disciplinas escolares, é o primeiro momento em que este autor elabora uma noção sobre a cultura escolar. Nesse texto Frago se posiciona a favor da singularidade de cada instituição escolar na constituição de uma cultura escolar própria, preferindo o termo culturas escolares, no plural para melhor caracterizar essa situação. Ele considera a cultura escolar como o "conjunto de aspectos institucionalizados" da escola, e a define da seguinte maneira: "Y si, es cierto, la cultura escolar es toda la vida escolar: hechos e ideas, mentes y cuerpos, objetos y conductas, modos de pensar, decir y hacer" (FRAGO, 1995, p. 69 - o negrito é nosso). Situar a cultura escolar enquanto a "vida da escola" supõe entender que há uma produção cultural que é específica da instituição escolar (de cada escola) e que ela tem uma dinâmica própria para perpetuar e se modificar no tempo e no espaço. A cultura escolar é viva e precisa ser situada no tempo e no espaço, elementos fundantes da mesma, juntamente com a linguagem (ibid.). Para Frago:

Estas tres dimensiones o aspectos - el espacio, el tiempo y el lenguaje o modos de comunicación - afectan al ser humano de lleno, en sus pensamientos y actividades, de modo individual, grupal y como especie en relación con la naturaleza de la que forma parte. Conforman su mente y sus acciones. Conforman y son conformadas, a su vez, por las instituciones educativas (ibid., p. 69).

Um aspecto central na elaboração teórica deste autor é a sua posição sobre a tensão entre inovação e/ou criação e reprodução e persistências no campo escolar. Como vimos anteriormente Julia e Chervel se posicionam claramente a favor das possibilidades criativas da escola. Nesse sentido, Frago é mais próximo da idéia de persistência, de reprodução da cultura escolar consolidada

4 No caso específico da Educação Física brasileira este autor cobra ainda mais relevância por ter sido o orientador de pós-doutorado do Prof. Marcus Taborda de Oliveira em 2008. 
na escola, sem, porém, desconhecer as possibilidades de mudança. Esse aspecto ganha relevância, uma vez que o problema abordado com maior profundidade pelo autor (e que em boa medida orienta o interesse dele pela cultura escolar) é o da relação entre as reformas educacionais e a cultura escolar. No livro publicado na Espanha em 2002, e que leva o título de "Sistemas educativos, culturas escolares y reformas: continuidades e cambios", é reelaborado o conceito e apresentado de forma mais ampla. Neste momento, o autor não deixa dúvidas sobre o entendimento de que a cultura escolar tende à reprodução, conceituando-a da seguinte maneira:

La cultura escolar, así entendida, estaría constituida por un conjunto de teorías, ideas, principios, normas, pautas, rituales, inercias, hábitos y prácticas (formas de hacer y pensar, mentalidades y comportamientos) sedimentadas a lo largo del tiempo en forma de tradiciones, regularidades y reglas de juego no puestas en entredicho, $y$ compartidas por sus actores en el seno de las instituciones educativas. [...] Sus rasgos característicos serían la continuidad y la persistencia en el tiempo, su institucionalización y una relativa autonomía que le permite generar productos específicos como las disciplinas escolares (FRAGO, 2002, p. 59)

Vemos neste caso que o autor se posiciona claramente a favor de uma compreensão de cultura escolar na qual prima a estabilidade, a regularidade, a reprodução, porém não a reprodução do sistema macro-social, mas reprodução, a persistência da maneira específica em que a escola produz a sua dinâmica de funcionamento. Vemos aqui um descolamento da escola com relação ao mundo que a circunda, no sentido de primar nela uma maneira de se fazer a vida escolar que tende a permanecer e a resistir a mudanças. Por tal motivo, as regras que regem a cultura escolar (a maior parte delas tácitas) não são, normalmente, questionadas, discutidas, problematizadas. Nesse sentido, a transmissão das regras de geração em geração permitem aos atores do cotidiano escolar: integrar-se e interagir nas instituições, enfrentar as situações cotidianas relacionadas ao ensino e sobreviver às reformas, reformulando-as, reinterpretando-as.

Com relação às mudanças o autor é muito cauteloso sobre os possíveis impactos das mesmas nas culturas escolares. Na leitura de Frago as reformas educacionais fracassam por não levar em consideração a cultura escolar. 
Las culturas escolares cambian, solo que de forma gradual y lenta, en general a largo plazo aunque en fases de intensidad o ritmos diferentes. Además, la innovación y el cambio sólo pueden originarse y producirse en el seno de las mismas, y tomando conciencia al mismo tiempo, quienes las promueven, de cuáles son los rasgos y elementos que caracterizan dichas culturas, y de cómo estos rasgos y elementos pueden originar resistencias y obstáculos o, por el contrario, apoyos y soportes en los que asentar los procesos de cambio. (FRAGO, 2004a, p. 71)

O alerta acima nos serve como uma valiosa chave de leitura para orientar os trabalhos de pesquisa sobre as mudanças educacionais no Brasil e na América Latina implementadas na década de 90 e que tiveram conseqüências altamente problemáticas para a Educação e particularmente para a Educação Física. Voltaremos a este ponto no último tópico do texto.

Entendemos que este aporte teórico é altamente relevante para compreendermos as maneiras de inserção de um professor na escola, as forças que intervém nesse processo e que operam muito mais no sentido da adequação dos novos atores às regras estabelecidas, do que no sentido de potencializar as mudanças. O trabalho de Luciano de Almeida e Paulo Fensterseifer no âmbito da pedagogia da Educação Física brasileira merece ser destacado neste momento (ALMEIDA, FENSTERSEIFER, 2007). Os autores demonstram como aconteceu o processo de socialização profissional em uma escola de uma professora que ingressou no curso de licenciatura em Educação Física motivada pela transformação da realidade por ela experienciada como aluna da Educação Física escolar, e cuja formação inicial esteve pautada pela pedagogia progressista da Educação Física. Essa professora transita desde uma prática inovadora a uma prática tradicional. Depois de transcorrido um certo tempo (não especificado no trabalho) ela se percebe reproduzindo o modelo de aulas imperante na escola, que era muito próximo daquele que ela vivenciara e criticara enquanto aluna da Educação Física escolar. Os autores atribuem esse processo ao fato de haver uma cultura escolar que leva os atores do cotidiano escolar a ela se moldarem, muitas vezes imperceptivelmente. Embora Almeida e Fensterseifer não recorram ao conceito elaborado por Frago de maneira direta, eles o fazem de maneira indireta pela referência a Tarcísio Mauro Vago, que, por sua 
Ano XXI, n 32/33, junho e dezembro/2009

vez, se vale do conceito cunhado pelo pesquisador espanhol.

Retomando a discussão sobre a relação entre reformas educacionais e cultura escolar, Frago entende que as reformas são normalmente ineficazes na transformação do cotidiano escolar por diversos motivos. Os dois mais relevantes são que elas vêm "de cima" (FRAGO, 2002) e não consideram a realidade específica dos contextos escolares concretos, as culturas escolares. Nesse sentido, o autor entende que essas últimas readequam e adaptam as reformas às suas formas específicas de fazer seu cotidiano, à vida das escolas, transformando, assim, seu caráter original. Por outro lado, as reformas (e poderíamos incluir aqui também as políticas públicas para a educação e a educação física) são elaboradas com o concurso entre dirigentes educacionais e especialistas educacionais, os quais produzem culturas pautadas por princípios completamente diferentes daqueles que regem a cultura dos professores que atuam nas escolas. Enquanto os primeiros se orientam pela urgência dos tempos políticos e por uma postura messiânica, e os segundos pela produção de uma linguagem criptográfica que soa como uma linguagem estrangeira aos ouvidos dos professores, esses últimos se orientam por preceitos práticos e elaborações de caráter prescritivo (FRAGO, 2002, 2004a).

Para ilustrar esse aspecto nos valemos do estudo de Marcus Aurélio Taborda de Oliveira que teve como objeto a relação entre as prescrições para a Educação Física escolar presentes na Revista Brasileira de Educação Física e Desportos de 1968 a 1984, nos Programas de Educação Física da Prefeitura Municipal de Curitiba de 1970 a 1984 e as falas dos professores que atuaram no período da ditadura militar (TABORDA, 2001, 2002). O autor pretende demonstrar como as diretrizes e prescrições oficiais para a Educação Física eram reapropriadas pelos professores que atuavam como professores de Educação Física escolar na rede pública de Curitiba. Oliveira elabora uma crítica severa às leituras críticas da Educação Física escolar como um espaço de mera reprodução do esporte, tal como ele se manifesta no contexto macro-social, calcado na lógica do esporte espetáculo e de rendimento, as quais ele considera abstratas e generalizantes. Ele entende que os professores são agentes ativos que a partir das "táticas do cotidiano" (CERTEAU, 1994) resistem, subvertem e recriam as formas e orientações do esporte e da Educação Física oriundas de outras instituições sociais, como a instituição esportiva e o Estado. A partir das 
análises realizadas o autor conclui com relação às diretrizes oficiais para a Educação Física escolar no período ditatorial que:

[...] a menos que houvesse o consentimento dos diversos agentes sociais, as políticas educacionais não teriam condições de consolidar-se no interior das escolas. Até porque a escola pode desenvolver uma dinâmica própria de organização que, sem dúvida, relaciona-se com o plano cultural mais amplo, mas que interage com ele para manifestar-se e para autogerir-se (OLIVEIRA, 2002, p. 71).

Embora, este autor não utilize o recurso a Frago podemos identificar na sua análise uma posição próxima do autor espanhol sobre a relativa impermeabilidade da cultura escolar com relação aos condicionamentos macro-estruturais. Contudo, cumpre destacar que há uma diferença importante entre eles sobre a tendência reprodutora de si mesma (no caso de Frago) e criadora (no caso de Oliveira) sobre o caráter fundamental da cultura escolar.

Por fim, e avançando de maneira esquemática, apresentamos o último aspecto constitutivo da cultura escolar para Antonio Viñao Frago. A cultura escolar, embora conte com elementos que possam ser considerados universais, precisa ser entendida na sua singularidade, na forma como se constitui em cada estabelecimento escolar (FRAGO, 2002). Porém, a cultura escolar de cada escola não é de forma alguma monolítica, mas funciona como um mosaico que é configurado por diversas culturas presentes no interior de cada escola e fora dela. Essas culturas se caracterizam pelo nível educacional, fundamental e médio (FRAGO, 2004b), pelos atores do cotidiano escolar, dos gestores da política educacional e dos especialistas educacionais (FRAGO, 2004a) e pelos enquadramentos legais em que funcionam os sistemas educacionais (FRAGO, 2002). Nas palavras abaixo se encontra sintetizada esta idéia:

Hay, pues, culturas específicas de cada centro docente, de cada nível educativo y de cada uno de los grupos de actores que intervienen em la vida cotidiana de las instituciones de enseñanza, así como subculturas más específicas. Pero dichas instituciones no operan en el vacío. Actúan dentro de un marco legal y de una política determinada que tiene su propia cultura (FRAGO, 2002, p. 65).

A seguir faremos uma análise do pesquisador da Educação Física brasileira que mais fortemente 
e de maneira mais prolongada tem trabalhado com o conceito de cultura escolar como sua principal baliza teórica, Tarcísio Mauro Vago. Embora sejam diversas as publicações de Vago referenciadas no conceito de cultura escolar (VAGO, 1996, 1999a, 1999b, 2000a, 2000b, 2003) observamos nelas um denominador comum: o um alto grau de autonomia concedido à escola com relação aos condicionamentos estruturais. Nesse sentido, o autor entende que devem ser compreendidos os processos de mediação que acontecem entre a escola e o meio externo, porém sempre se fica com a sensação que essa relação será sempre em favor da autonomia da escola, que "dribla" as coerções externas. É assim quando ele se refere ao esporte escolar (VAGO, 1996), quando ele propõe a cultura escolar como uma via privilegiada de acesso ao cotidiano escolar (VAGO, 1999a) ou quando ele propõe uma agenda de pesquisa para a Educação Física escolar (VAGO, 2003). Vejamos, a título de exemplo, o que Vago nos diz sobre os agentes escolares:

[...] os agentes escolares não são consumidores passivos de saberes impostos de fora para dentro. São produtores de um saber encarnado, vivo, instituidor, aberto, em movimento: a escola e seus agentes não são objetos manipuláveis do conhecimento científico, racionalizado, pronto, mas lugar de sujeitos praticantes e produtores de conhecimento. (VAGO, 2003, p. 213)

Para nós Vago realiza uma leitura muito aligeirada da proposta de Frago, aproximando-o da postura de Forquin, Julia e Chervel o que pode distorcer a proposta teórica do pesquisador espanhol, por causa do algo grau de espaço para a mudança, para a inovação que é proposta pelo pesquisador brasileiro. Segundo Tarcísio M. Vago, para compreender a cultura escolar devemos atender a diversas dimensões, sendo elas as representações sobre a Educação Física, os tempos e os espaços escolares, os conhecimentos, as disciplinas e as práticas escolares e os sujeitos ou agentes escolares (VAGO 2003).

É importante destacar que os trabalhos de Vago se caracterizam por serem textos ensaísticos. Somente em três ocasiões ele publica trabalhos que são frutos de pesquisas empíricas para discutir a cultura escolar (VAGO, 1999b, 2000a, 2000b). Esses textos, que tem por base a sua tese de doutoramento, abordam a problemática da ginástica no ensino público de Belo Horizonte no início do século XX. Neles se revela, paradoxalmente, uma visão da cultura escolar mais 
próxima da reprodução de coerções sociais do que da criação. Embora o autor reconheça que as prescrições oficiais não eram implantadas de maneira linear em virtude das precariedades da infra-estrutura e da resistência da população, ele constata a predominância da formação dos corpos que acontecia na gymnastica como sendo amplamente pautada pela lógica do disciplinamento corporal, conforme prescrita pelas diretrizes oficiais. Reproduzimos a passagem de um dos textos que ora discutimos e que retrata claramente essa análise:

ESpecificamente, os impasses em que a ginástica esteve envolvida naquele momento revelam comprometimentos à prática das representações produzidas acerca do seu lugar na educação das crianças. Em outras palavras, impuseram limitações à materialização do primado orientador da "gymnastica" como prática corretora e constitutiva dos corpos das crianças. Não impedem de ver, contudo, o investimento de uma época em que os agentes escolares se lançaram sobre as crianças na tentativa de realizar a sua "educação physica", de cultivar seus corpos para fazê-los belos, fortes e saudáveis - foi esse investimento que provocou o enraizamento escolar da ginástica em Minas Gerais, particularmente em Belo Horizonte (VAGO, 2000a, p. 16)

A partir da análise dos textos de Tarcísio M. Vago, podemos afirmar que ele estabelece uma relação ambígua com o conceito de cultura escolar. Essa ambigüidade transita entre uma postura amplamente favorável à concepção de cultura escolar como espaço de criação, de produção de saberes e fazeres próprios da escola quando ele trabalha na perspectiva da pedagogia da educação física; e outra mais favorável a entender a cultura escolar como um espaço de reprodução, quando se trata de trabalhos historiográficos. Com relação à primeira postura, a perspectiva pedagógica, consideramos oportuna o alerta que fazem Faria Filho et al. (2004) com relação a boa parte das pesquisas referenciadas no conceito de cultura escolar. Eles nos dizem que: "[...] em boa parte das vezes, estamos lidando com exercícios de prescrição de práticas, ou seja, em boa parte estamos lidando mais com culturas escolares prescritas do que com culturas escolares praticadas no interior das escolas" (p. 154).

Depois da análise dos conceitos de cultura escolar e sua recepção no campo acadêmico brasileiro, apresentaremos a seguir 
Ano XXI, n 32/33, junho e dezembro/2009

possíveis desdobramentos de pesquisa pautada pelo conceito de cultura escolar.

\section{Considerações finais: princí- pios metodológicos e desdo- bramentos de pesquisa}

No decorrer do presente trabalho nos aproximamos da grande complexidade do objeto com o qual nos deparamos. Vimos que não é possível reduzir o objeto à dimensão interna da escola, nem tão somente a dimensão externa (estrutural), nem muito menos assumir que a cultura escolar segue um percurso padronizado na sua constituição. Colocado em outros termos a cultura escolar somente pode ser compreendida se olharmos para a complexa rede de relações de fatores intra- e extraescolares, bem como para os percursos de formação inicial e continuada dos professores que atuam nas escolas. Entendemos que estes são os protagonistas do trabalho e que não é possível abordar este objeto à margem do seu trabalho. Por outro lado, entendemos que é relevante conceber o campo escolar como espaço no qual se podem/devem identificar as tensões, as acomodações, as determinações, táticas do cotidiano e as rupturas com a estrutura que os atores presente nele produzem.
Entendemos que o princípio teórico-metodológico proposto por Coulon (1995) é uma rica pista para orientar estes estudos. Ele, se referindo às pesquisas de cunho etnometodológico em educação, afirma que:

A vida social é feita de inúmeros marcadores sociais, sem os quais ela não seria possível. Deve-se notar que essas marcas não existem a-priori, fora dos atores; pelo contrário, são produzidas, continuamente, através das interações dos membros da sociedade, grupo, sala de aula, reunião entre amigos, conversas telefônicas, declarações amorosas, etc. Uma vez que forem identificados tais marcadores, saberemos reconhecê-los ulteriormente (COULON, 1995, p. 323)

Assumimos, baseados na premissa acima, que a cultura escolar não é imune às coerções externas, porém, para elas serem aceitas precisam ser verificadas no interior das escolas, mais ainda, nas maneiras singulares a partir das quais os atores do cotidiano escolar com elas se relacionam.

A centralidade da investigação das práticas é uma das principais contribuições da linha de pesquisas desenvolvida a partir do conceito de cultura escolar (FARIA 
FILHO et al., 2004). Nesse sentido, nesse sentido entendemos que este horizonte de pesquisa nos abre a possibilidade de problematizar a "Educação Física viva" à qual nos convida Betti (2005) a retornar.

Também consideramos que esta perspectiva teórica possibilita nos mantermos em consonância com uma maneira de produzir conhecimento, que nos permita enfrentar o problema acerca da identidade da Educação Física. Segundo Fensterseifer (2001) a questão da identidade da Educação Física não deve ser formulada nos termos tradicionais a partir da pergunta: "O que é a Educação Física?", que implicaria a procura por um fundamento metafísico da nossa área de conhecimento, retirando a dimensão histórica da sua constituição. Para o autor, essa questão deveria ser formulada no sentido de: "O que a Educação Física vem sendo?", isto é, o problema da identidade da Educação Física deveria estar enraizado no horizonte de historicidade da nossa área, das suas diversas manifestações no tempo e no espaço. Com base nessas idéias e para construir conhecimento consistente para a Educação Física escolar, consideramos que a pesquisa da cultura escolar deve preservar duas posturas imprescindíveis; a humildade epistemológica dos atores do campo acadêmico com relação aos atores do campo escolar (SANTOS, BRACHT, ALMEIDA, 2009), e a permanente vigilância para evitar construir "culturas prescritas", obscurecendo a possibilidade de compreender as "culturas praticadas" (FARIA FILHO, et al., 2004).

Para finalizar este artigo apresentamos a seguir alguns possíveis desdobramentos de pesquisa, que nos parecem relevantes para aprofundar os estudos da(s) cultura(s) escolares praticadas nas escolas brasileiras e compreender facetas relevantes do devir dessa área de conhecimento no contexto escolar. ${ }^{5}$ Dito de outra maneira, fechamos abrindo possibilidades.

Um primeiro problema a ser investigado com maior profundidade é a reforma educacional da década de 90 e as relações estabelecidas pelos atores do campo acadêmico da pedagogia da Educação Física brasileira nesse movimento. Entendemos que precisa ser problematizada a relação entre o notório avanço registrado no campo acadêmico da pedagogia da Educação Física no Brasil, as críticas feitas por esse movimento endereçadas ao esporte escolar praticado nos moldes

5 Utilizaremos neste momento alguns elementos surgidos de uma pesquisa comparada da qual participamos que está referenciada na categoria de cultura escolar. 
Ano XXI, n 32/33, junho e dezembro/2009

do esporte formal, do esporte de rendimento, as mudanças estruturais do sistema educacional brasileiro, decorrentes da implantação de políticas neoliberais que implicaram numa fortíssima retração do Estado, e as mudanças ocorridas ao interior das escolas, em particular nas aulas do componente curricular Educação Física. Trabalhamos com a hipótese de que o discurso instituído pelos novos atores do campo acadêmico, muito distante da linguagem dos professores de Educação Física escolar, e calcado em uma forte crítica ao esporte de rendimento, levou a uma eliminação de uma prática presente nas escolas, balizada pela concepção do rendimento físicoesportivo, criando-se uma lacuna até o momento não preenchida. Essa situação levou a que a Educação Física escolar se situasse na condição do entre "não mais e o ainda não" (FENSTERSEIFER, 2001). Em particular, esta situação parece estar mais fortemente instalada entre os professores que vivenciaram essa transição durante sua atuação profissional. O problema de pesquisa esboçado nos parece da maior relevância para compreendermos uma década que parece ter sido muito mais "prescritiva" do que "compreensiva".

Outro objeto a ser investigado, é a velha problemática entre o esporte escolar e o esporte de rendimento e a legitimação da Edu- cação Física. Embora esse assunto tenha sido amplamente debatido são escassos os estudos empíricos que abordem esse problema. A título de exemplo citamos o estudo de Bracht et al., (2005) realizado no Colégio Estadual do Espírito Santo, que constatou uma fortíssima imbricação entre a legitimidade da Educação Física escolar e os resultados das equipes escolares em competições de esporte escolar, via de regra, realizadas nos moldes do esporte formal. Esse estudo guarda consonância com a pesquisa de Cardoso (1999) que confirma essa relação em uma pesquisa realizada em um estabelecimento escolar do sudoeste do Estado do Paraná. Alargando este objeto precisam ser entendidas também as relações entre a "privatização" da Educação Física, na medida em que se isenta os alunos da participação nas aulas desse componente curricular, mediante a comprovação da prática de atividades físicas fora do âmbito escolar. Precisam ser compreendidas com base empírica sólida as implicações entre a cultura escolar da Educação Física, a legitimidade da Educação Física como componente curricular e outras instituições sociais vinculadas ao campo da cultura corporal, tanto no âmbito público quanto privado.

Por fim, apontamos um instigante e complexo problema, 
qual seja a relação entre o conhecimento que identifica a escola moderna e o conhecimento específico da Educação Física escolar e de outras disciplinas como a Educação Artística, que podem ser situadas dentro de um registro epistemológico próximo. Souza e Galvão (2005) entendem que:

[...] os dois estudos [a Educação Física e a Educação Artística] se detêm sobre dimensões da vida de homens e mulheres que não estão diretamente relacionadas aquilo a que a escola tradicionalmente se propôs a trabalhar, ou seja, a atividade cognitiva, intelectual. Lidam, por outro lado, com o corpo e a sensibilidade (p. 402).

Se entendermos que o projeto moderno de educação escolar está pautado por princípios outros, que aqueles vinculados do que poderíamos denominar de uma educação estética (VAZ, 2001), precisamos compreender com a escola contemporânea se relaciona com uma concepção de conhecimento que se inscreve em um registro diferente do conhecimento discursivo, pautado pela lógica da ciência clássica. A relação entre o conhecimento tradicional da escola (ainda?) moderna e aquele específico da Educação Física escolar precisa ser tematizado. Podemos nos perguntar neste caso se a concepção tradicional da Educação Física como uma "atividade" de treinamento corporal e de caráter compensatória para as atividades "sérias" da escola, não seria muito mais funcional ao projeto moderno de escola do que uma concepção renovada do conhecimento desse componente escolar, tal como proposta pelo movimento renovador da Educação Física brasileira, em particular pela vertente progressista?

Estes são problemas que precisam ser compreendidos a partir do "sendo" da Educação Física escolar, da sua materialidade, da sua historicidade, do seu enraizamento no tempo e no espaço, das formas específicas e singulares de sua expressão. Essas são questões para uma próxima conversa...

\section{REFERÊNCIA}

AZANHA, J. M. P. Cultura escolar brasileira - um programa de pesquisa. Revista USP, São Paulo, p. 37-40, dez.-jan.fev.1990-1991.

BERTO, Roseany C. e SCHNEIDER, Omar Saúde, higiene, Educação Física e cultura escolar: um olhar sobre a infância a partir da Revista Educação Physica Disponível em: http://www. 
Ano XXI, n 32/33, junho e dezembro/2009

proteoria.org Acessado em: 10/07/2008.

BETTI, M. Sobre teoria e prática: manifesto pela redescoberta da Educação Física. Revista Digital Efdeportes, ano X, n. 90, dez. 2005. Disponível em: http:// www.efdeportes.com

BRACHT, V. Educação Física e aprendizagem social. Porto Alegre: Magister, 1992.

A constituição das teorias pedagógicas da Educação Física. Cadernos CEDES, Campinas, ano XIX, n. 48, p. 69-88, 1999.

Educação Física e ciência: cenas de um casamento (in)feliz. Ijuí: UNIJUÍ, $1999 b$.

BRACHT, V. et al. A prática pedagógica em Educação Física: a mudança a partir da pesquisaação. In: Anais XII CONBRACE. CD-Room. Caxambú: CBCE/ DN, 2001.

Pesquisa em ação: Educação Física na escola. Ijuí: UNIJUÍ, 2003.

Itinerários da Educação Física na escola: o caso do Colégio Estadual do Espírito Santo. Movimento, Porto Alegre, v. 11, n. 4, p. 9-21, jan.-abr. 2005.

CARDOSO, O. M. Professor de Educação Física ou técnico desportivo: quem vale mais? Com a palavra os atores envolvidos. IN: Teixeira, E. Educação; algumas reflexões sobre política, teoria e prática. Pato Branco: Liceu Teixeria, 1999.

CERTEAU, $M$. de A invenção do cotidiano - vol. 1 Artes de fazer. Petrópolis: Vozes, 1994.

CHERVEL, A. Historia de lãs disciplinas escolares - reflexiones sobre um campo de investigación. Revista de Educación, Madri, n. 295, p. 59-111, 1991.

COULON, A. Etnometodologia e educação. In: Sociologia da educação - 10 anos de pesquisa. FORQUIN, J.-C. (Org.), p. 299350. Petrópolis: Vozes, 1995.

FARIAS, G. O.; SHIGUNOV, V., NASCIMENTO, J. V. do. $O$ percurso profissional dos professores de Educação Física: rumo à prática pedagógica. In: Anais XII CONBRACE. CD-Room. Caxambú: CBCE/DN, 2001.

FARIA FILHO, L. M. de et al. A cultura escolar como categoria de análise e como campo de investigação na história da educação brasileira. Educação e Pesquisa, São Paulo, v. 30, n. 1, p. 139-159, jan.-abr. 2004.

FENSTERSEIFER, P. E. Educação Física na crise da modernidade. ljuí: UNIJUÍ, 2001.

FIGUEIREDO, Z. C. C. Formação docente em Educação Física: experiências sociais e relação com o saber. Movimento, Porto Alegre, v. 10, n. 1, p. 89-111, jan.-abr. 2004. 
FORQUIN, J.-C. Escola e cultura as bases sociais e epistemológicas do conhecimento escolar. Porto Alegre: Artes Médicas, 1993.

Saberes escolares, imperativos didáticos e dinâmicas sociais. Teoria e Educação, Porto Alegre, n. 5, p. 28-54, 1992.

FRAGO, A. V. Historia de La educación e historia cultural - posibilidades, problemas, cuestiones. Revista Brasileira de Educação, São Paulo, n. 0, p. 63-82, set.-dez., 1995.

Sistemas escolares, culturas escolares y reformas: continuidades y cambios. Madri: Morata, 2002.

Bibliotecas escolares, "culturas escolares" y formación de profesores. Educação e Realidade, Porto Alegre, v. 29, n. 2, p. 65-87, jul.-dez. 2004a.

La dirección escolar: un análisis genealógico-cultural. Educação, Porto Alegre, n. 2, v. 53, p. 367415, mai.-ago. 2004.

JULIA, D. A cultura escolar como objeto histórico. Revista Brasileira de História da Educação, São Paulo, n. 1, p. 9-43, jan.-jul. 2001.

KUNZ, E. Educação Física - ensino e mudança. ljuí: UNIJUÍ, 1991. Transformação didáticopedagógica do esporte. Ijuí: UNIJUÍ, 1994.

LOCATELLI, A. B.; FERREIRA NETO, A.; DOS SANTOS, W. A teoria do saber docente na Educação e na Educação Física. In: Anais XIII CONBRACE. CD-Room. Caxambú: CBCE/DN, 2003.

MOLINA NETO, V. Etnografia: uma opção metodológica para alguns problemas de investigações no âmbito da Educação Física. In: MOLINA NETO, V. TRIVIÑOS, A. N. S. (org.) A pesquisa qualitativa em Educação Física: alternativas metodológicas. p. 107-139, Porto Alegre: Editora da UFRGS/Sulina, 1999.

MOLINA NETO, V.; SANTINI, J. A síndrome do esgotamento profissional em professores de Educação Física: um estudo da rede municipal de ensino de Porto Alegre. Revista Brasileira de Educação Física e Esportes, São Paulo, v. 19, n. 3, p. 209222, jul.-set. 2005.

MOLINA NETO, V.; SCHNEIDER, A. O conhecimento dos professores de Educação Física nas escolas públicas de Porto Alegre. Disponível em: http://www.esef. ufrgs.br/f3p-efice/molina $\% 203$. pdf Acesso em: 20/08/2009.

OLIVEIRA, M. A. T. de Educação Física escolar e ditadura militar no Brasil (1968-1984): história e historiografia. Educação e Pesquisa, São Paulo, v. 28, n. 1, p. 51-75, jan.-jun. 2002.

PEREZ GÓMEZ, A. I. A cultura escolar na sociedade neoliberal.

Porto Alegre: Artmed, 2001. PESSANHA, E. C.; DANIEL, M. E. B.; MENEGAZZO, M. A. Da 
história das disciplinas escolares à história da cultura escolar: uma trajetória de pesquisa. Revista Brasileira de Educação, São Paulo, n. 27, set.-dez. 2004.

SANTINI, J. O processo de abandono da carreira docente dos professores de Educação Física da rede municipal de ensino de Porto Alegre: a síndrome do esgotamento profissional (SEP). Um estudo introdutório. In: Anais XIII CONBRACE. CD-Room. Caxambú: CBCE/DN, 2003.

SANTOS, N. Z. dos; BRACHT, V.; ALMEIDA, F. Q. de. Vida de professores de Educação Física: o pessoal eo profissional no exercício da docência. Movimento, Porto Alegre, v. 15, n. 02, p. 141-165, abr.-jun. 2009.

VAGO, T. M. O "esporte na escola" e o "esporte da escola" da negação radical para uma relação de tensão permanente um diálogo com Valter Bracht. Movimento, Porto Alegre, ano III, n. 5, 1996.

Intervenção e conhecimento na escola: por uma cultura escolar de Educação Física. In: GOELLNER, S. V. (Org.) Educação Física/Ciências do Esporte - conhecimento e intervenção. p. 17-36. Florianópolis: Colégio Brasileiro de Ciências do Esporte, 1999a.

Início e fim do século $X X$ : maneiras de fazer educação física na escola. Cadernos Cedes,
Campinas, ano XIX, n. 48, p. 3051, agosto 1999b.

Cultura escolar, cultivo de corpos: a gymnastica como prática constitutiva de corpos de crianças no ensino público primário de Belo Horizonte (1906-1920). Anais da $23^{\text {a }}$ Edição da ANPED. Caxambú, 2000a. Disponível em: http://www.anped.org.br/ reunioes/23/textos/0227t.pdf Acesso em: 15/08/2009.

Cultura escolar, cultivo de corpos: Educação Physica e gymnastica como práticas constitutivas dos corpos de crianças no ensino público primário de Belo Horizonte (1906-1920). Educar, Curitiba, n. 16, p. 121-135, 2000b.

Educação Física na cultura escolar: caminhos para a intervenção e a pesquisa. In: BRACHT, V.; CRISORIO, R. (Org.) A Educação Física no Brasil e na Argentina: identidade, desafios e perspectivas. p. 197-222. Campinas: Autores Associados, 2003.

VAZ, A. Técnica, esporte, rendimento. Revista Movimento, Porto Alegre, v. 7, p. 87-99, junho 2001.

WILLIS, P. Aprendendo a ser trabalhador. Escola, Resistência e Reprodução Social. Porto Alegre: Artes Médicas, 1991.

Recebido: Abril/2010 Aprovado: Agosto/2010 